\title{
Formal Auditory Training with Individuals after Traumatic Brain Injury
}

\author{
Andréa Tortosa Marangoni, Ítalo Capraro Suriano, Ana Karina Lima Buriti, Daniela Gil* \\ Universidade Federal de São Paulo-UNIFESP, São Paulo, Brazil \\ Email: *danielagil@hotmail.com
}

How to cite this paper: Marangoni, A.T., Suriano, I.C., Buriti, A.K.L. and Gil, D. (2017) Formal Auditory Training with Individuals after Traumatic Brain Injury. Health, 9, 975-986.

https://doi.org/10.4236/health.2017.96070

Received: March 27, 2017

Accepted: June 27, 2017

Published: June 30, 2017

Copyright (C) 2017 by authors and Scientific Research Publishing Inc. This work is licensed under the Creative Commons Attribution International License (CC BY 4.0).

http://creativecommons.org/licenses/by/4.0/ (c) (i) Open Access

\begin{abstract}
Purpose: Establishing the effects of a formal auditory training program on individuals, after a traumatic brain injury by means of behavioral and electrophysiological tests. Study Design: Longitudinal study. Setting: Study conducted at the electrophysiology clinic of the Federal University of São Paulo. Patients: Nine individuals with normal hearing, 20 to 37 years old, who were exposed to severe traumatic brain injury (score of $3-8$ on the Glasgow Coma Scale upon hospital admission), 6 - 24 months earlier (11 months on average) and had imaging tests showing diffuse axonal injury with or without associated focal lesion. Intervention $(s)$ : subjected to a formal auditory training program in an acoustic booth involving eight 45 -minute sessions aiming at training the auditory temporal order judgment (frequency and duration of sounds), auditory closure, and figure-ground separation skills for verbal and nonverbal sounds in monotic and dichotic listening tasks. The sessions and activities, in each session, were organized in increasing order of complexity to challenge the auditory system. In order to establish the efficacy of the auditory training, all participants were subjected to behavioral and electrophysiological assessments of the auditory processing, before and after the formal auditory training. Results. On the electrophysiological assessment, the absolute latencies of waves III and $\mathrm{V}$, and of interpeak interval I-V decreased after the auditory training. However, the P300 did not exhibit a significant difference in either the latency or the amplitude parameters. Regarding the behavioral assessment of the auditory processing, it was verified that adequacy of the auditory figure-ground skills for verbal sounds, and the temporal order judging skills. Conclusions. individuals with diffuse axonal injury following a severe traumatic brain injury exhibited an improvement of central auditory processing after formal auditory training, as manifested on electrophysiological and behavioral assessments.
\end{abstract}

\section{Keywords}

Hearing, Evoked Potentials, Auditory, Neuronal Plasticity, Brain Injuries 


\section{Introduction}

Traumatic brain injury (TBI) essentially consists in the result of physical aggression on the skull and its contents caused by impact and acceleration/deceleration of the brain inside the skull. The lesions caused in the brain during such events can be primary or secondary [1].

Primary injuries refer to those that occur at the moment of trauma and include extradural and subdural hematomas, contusions and diffuse axonal injury. Brain deformation caused by extreme acceleration and deceleration affects nerve fibers, including the neural substrate responsible for hearing, thus resulting in central auditory deficits, particularly the case in diffuse axonal injury, which involves several areas such the cortical and subcortical auditory regions [2].

Due to the high frequency of brainstem and cortical lesions in TBI patients [3], the performance of long and short-latency auditory evoked potentials (AEP) and behavioral assessment of Central Auditory Processing (CAP) are important in the evaluation of the auditory function at the brainstem and in the subcortical and cortical regions. Many TBI patients exhibit Central Auditory Processing Disorder (CAPD) which can only be identified by means of electrophysiological techniques and tests for central auditory function [2].

As a function of the above mentioned alterations can be found in TBI patients and can affect communication, including hearing, speech and other cognitive functions, rehabilitation programs might benefit these individuals by contributing to improve their quality of life.

Spontaneous recovery following brain injury, more specifically TBI, occurs within the first 3 months [4], particularly in the first month [5]. After this initial period, the injured brain can modify and readjust itself through stimulationinduced neuronal plasticity, for which the limiting factors are the size, site and severity of the injury.

Formal auditory training (FAT) involves auditory stimulation aimed at maximizing the effects of central nervous system plasticity [6]. It comprises a set of strategies to develop or rehabilitate the auditory skills that participate in the linguistic and phonemic processing needed to understand speech.

In addition to providing important information for the diagnosis, the AEP might be useful to monitor the treatment of TBI patients, giving evidence of changes in neural activity related to the auditory experiences induced by FAT. Due to its plasticity, the central nervous system (CNS) is able to reorganize itself as a function of the stimuli received; thus, changes in AEP latency and amplitude parameters can provide an objective measurement of that plasticity.

Several studies with different populations have shown that FAT induces neuroplasticity, i.e., the increase in the number or strength of neuronal synapses and/or synchrony, which is evidenced by an increase of amplitude and/or a reduction of latency in the AEP [7]-[17], resulting in behavioral changes [17]-[24].

Given the above, the aim of the present study was to determine the effects of a FAT program on individuals with TBI by means of behavioral and electrophysiological tests. 


\section{Methods}

The present study was conducted at the auditory processing and electrophysiological laboratories of the Auditory Disorders Class of the Federal University of São Paulo (Universidade Federal de São Paulo-UNIFESP) after approval by the institution's research ethics committee (ruling 0389/10).

The sample of this study consisted of nine individuals, chosen independently of the sex, as a consequence of the injury that occurred in the 2011 and 2012 period of the study, and it was necessary to meet the following inclusion criteria: individuals with severe closed TBI (score 3 - 8 on the Glasgow Coma Scale upon hospital admission), exclusively induced coma, diffuse axonal injury with or without associated focal lesion, time interval between trauma and enrollment in the study of 6 - 24 months, age between 18 and 37 years, of both genders, righthanded, with complete secondary education, and normal auditory threshold between 250 and $8000 \mathrm{~Hz}$.

Since we had very strict inclusion criteria, our sample size was reduced but homogenous, considering neurological damage.

All participants were subjected to the following procedures:

1) Clinical interview to collect data on hearing and TBI.

2) Behavioral and electrophysiological assessments and reassessments of CAP, before and after FAT. The electrophysiological assessment included brainstem (BAEP) and P300 long-latency (LLAEP) auditory evoked potentials. The behavioral assessment was performed in an acoustic booth and included the following tests: synthetic sentence identification test with ipsilateral (SSI-ICM) and a contralateral (SSI-CCM) competing message, pure-tone duration pattern test (DPT), staggered spondaic word test (SSW), and random gap detection test (RGDT).

3) FAT distributed among eight 45-minute sessions held twice a week, based on Pereira and Dias [25], and Dias and Gil [26].

FAT sessions followed an increasing order of complexity, as did the activities performed in each session, in order to promote intense stimulation and challenging activities to the auditory system.

The program included training of the temporal-order judgment, auditory closure and figure-ground skills for verbal and nonverbal sounds in monotic and dichotic listening tasks. Participants were requested to point to sentences and numbers and verbally repeat sounds or imitate a given sound pattern. The right and left ears were trained separately; thus, during training sessions to the right ear, participants were instructed to ignore the sounds presented to the left ear and vice-versa. Sound intensity level was fixed in the trained ear, gradually increasing in the other ear, thus inducing a positive to negative shift in the signalto-noise ratio, i.e., from the easiest to the most difficult, according to the DIID (Dichotic Interaural Intensity Difference) paradigm [27].

In each session, an accuracy level of approximately $70 \%$ was established to move on to the following phase, in order to maintain motivation and avoid frustrating the participants [18]. 
Once collected, data were statistically analyzed. The Wilcoxon test was used to compare the results of behavioral and electrophysiological assessments of CAP before and after FAT. Statistically significance is indicated by asterisks $\left(^{*}\right)$, and results bordering significance are indicated by pound signs (\#). The significance level adopted was 0.05 (5\%) and the confidence interval was 95\%.

\section{Results}

The sample comprised nine participants aged 20 to 37 years (27 years on average). Of these, 6 had completed secondary education, while 3 had in complete higher education. All participants had suffered severe TBI (average Glasgow score upon admission of 5.7) about 10 months prior to the study, which required hospitalization for a period of 50.6 days. All subjects in the study participated in formal auditory training by completing all proposed sessions.

All participants were male, had memory and attention complaints, speech comprehension difficulties in noisy environments, and difficulties to speak, read and/or write. Regarding the type of affliction, all patients presented diffuse axonal injury; 2 did not have associated focal lesion; 3 had subdural hematomas; 1 had an extradural hematoma; 1 hada temporal-lobe contusion; 1 had a frontaland temporal-lobe contusion, and 1 had both, subdural hematoma and temporal-lobe contusion.

Table 1 describes the results of the BAEP before and after FAT, showing reduced latency of all waves and interpeak intervals following the FAT, which was

Table 1. Absolute latencies of waves I, III, and V and of interpeak intervals I-III, III-V, and I-V before and after FAT.

\begin{tabular}{|c|c|c|c|c|c|c|c|c|c|}
\hline \multicolumn{2}{|c|}{$\begin{array}{c}\text { BAEP } \\
\text { Latency }\end{array}$} & \multirow{2}{*}{$\begin{array}{c}\text { Mean } \\
1.60\end{array}$} & \multirow{2}{*}{$\begin{array}{c}\text { Median } \\
1.59\end{array}$} & \multirow{2}{*}{$\begin{array}{c}\begin{array}{c}\text { Standard } \\
\text { deviation }\end{array} \\
0.11\end{array}$} & \multirow{2}{*}{$\begin{array}{c}\text { Q1 } \\
1.50\end{array}$} & \multirow{2}{*}{$\begin{array}{c}\text { Q3 } \\
1.68\end{array}$} & \multirow{2}{*}{$\begin{array}{r}\mathbf{N} \\
18\end{array}$} & \multirow{2}{*}{$\begin{array}{c}\text { CI } \\
0.05\end{array}$} & \multirow{3}{*}{$\begin{array}{r}\text { p-value } \\
0.679\end{array}$} \\
\hline & Before & & & & & & & & \\
\hline 1 & After & 1.59 & 1.60 & 0.09 & 1.50 & 1.62 & 18 & 0.04 & \\
\hline \multirow[b]{2}{*}{ III } & Before & 3.75 & 3.77 & 0.13 & 3.68 & 3.80 & 18 & 0.06 & \multirow[b]{2}{*}{$0.040^{*}$} \\
\hline & After & 3.70 & 3.68 & 0.10 & 3.63 & 3.80 & 18 & 0.05 & \\
\hline \multirow[b]{2}{*}{$\mathrm{V}$} & Before & 5.62 & 5.60 & 0.19 & 5.47 & 5.69 & 18 & 0.09 & \multirow[b]{2}{*}{$0.004^{\star}$} \\
\hline & After & 5.51 & 5.48 & 0.16 & 5.41 & 5.56 & 18 & 0.07 & \\
\hline \multirow{2}{*}{ I-III } & Before & 2.15 & 2.15 & 0.14 & 2.07 & 2.18 & 18 & 0.07 & \multirow{2}{*}{0.205} \\
\hline & After & 2.11 & 2.12 & 0.12 & 2.01 & 2.18 & 18 & 0.06 & \\
\hline \multirow{2}{*}{ III-V } & Before & 1.88 & 1.83 & 0.20 & 1.73 & 2.07 & 18 & 0.09 & \multirow{2}{*}{0.104} \\
\hline & After & 1.81 & 1.83 & 0.16 & 1.73 & 1.89 & 18 & 0.07 & \\
\hline \multirow{2}{*}{ I-V } & Before & 4.02 & 3.95 & 0.22 & 3.85 & 4.12 & 18 & 0.10 & \multirow{2}{*}{$0.011^{\star}$} \\
\hline & After & 3.92 & 3.87 & 0.18 & 3.78 & 4.00 & 18 & 0.08 & \\
\hline
\end{tabular}

Legend: Q1: first quartile; Q3: third quartile; N: number of individuals; CI: confidence interval. Wilcoxon test $\mathrm{p}<0.05$. 
statistically significant for the absolute latencies of waves III and V, and o for interpeak interval I-V.

As seen in Table 1, it was possible to detect an objective measure of neural plasticity in brainstem, reflected by the shortening of Waves III and V latencies.

Regarding the P300-LLAEP, Table 2 shows that neither the latency nor the amplitude parameters exhibited significant differences between assessments, i.e., before and after FAT.

Behavioral assessment results of CAP before and after FAT were expressed as percentages and showed significant improvements in the SSW, SSI-ICM, and DPT tests (Table 3).

Table 2. Latency (ms) and amplitude (mv) of the P3 component of P300-LLAEP before and after FAT.

\begin{tabular}{ccccc}
\hline \multirow{2}{*}{ P300 } & \multicolumn{2}{c}{ Latency } & \multicolumn{2}{c}{ Amplitude } \\
\cline { 2 - 5 } & Before & After & Before & After \\
\hline Mean & 330.3 & 343.8 & 7.36 & 6.06 \\
Median & 321.7 & 336.2 & 7.86 & 4.84 \\
Standard deviation & 43.0 & 38.1 & 2.46 & 3.14 \\
Q1 & 298.7 & 317.2 & 5.81 & 4.08 \\
Q3 & 350.5 & 361.0 & 8.99 & 8.12 \\
N & 16 & 18 & 16 & 18 \\
CI & 21.1 & 17.6 & 1.21 & 1.45 \\
p-value & & 0.178 & & 0.278 \\
\end{tabular}

Legend: Q1: first quartile; Q3: third quartile; N: number of individuals; CI: confidence interval. Wilcoxon test $\mathrm{p}<0.05$.

Table 3. Participants' performance in the behavioral assessment of AP before and after FAT.

\begin{tabular}{cccccccccc}
\hline \multicolumn{2}{c}{$\begin{array}{c}\text { Behavioral } \\
\text { assessment }\end{array}$} & Mean & Median & $\begin{array}{c}\text { Standard } \\
\text { deviation }\end{array}$ & Q1 & Q3 & N & CI & p-value \\
& Before & $84.0 \%$ & $86.3 \%$ & $11.4 \%$ & $75.0 \%$ & $93,8 \%$ & 18 & $5.3 \%$ & \\
SSW & After & $93.3 \%$ & $95.0 \%$ & $6.4 \%$ & $90.0 \%$ & $97.5 \%$ & 18 & $3.0 \%$ & $0.001^{*}$ \\
& Before & $97.2 \%$ & $100.0 \%$ & $7.5 \%$ & $100.0 \%$ & $100.0 \%$ & 18 & $3.5 \%$ & \\
SSI-CCM (-40) & After & $100.0 \%$ & $100.0 \%$ & $0.0 \%$ & $100.0 \%$ & $100.0 \%$ & 18 & $-\mathrm{x}-$ & 0,102 \\
& Before & $89.4 \%$ & $100.0 \%$ & $18.6 \%$ & $90.0 \%$ & $100.0 \%$ & 18 & $8.6 \%$ & \\
SSI-ICM (0) & After & $100.0 \%$ & $100.0 \%$ & $0.0 \%$ & $100.0 \%$ & $100.0 \%$ & 18 & $-\mathrm{x}-$ & $0.027^{*}$ \\
& Before & $71.7 \%$ & $75.0 \%$ & $23.1 \%$ & $52.5 \%$ & $90.0 \%$ & 18 & $10.7 \%$ & \\
SSI-ICM (-10) & After & $87.2 \%$ & $90.0 \%$ & $9.6 \%$ & $80.0 \%$ & $90.0 \%$ & 18 & $4.4 \%$ & $0.004^{*}$ \\
& Before & $80.7 \%$ & $86.6 \%$ & $16.2 \%$ & $73.0 \%$ & $90.0 \%$ & 9 & $10.6 \%$ & \\
DPT & After & $89.2 \%$ & $90.0 \%$ & $10.0 \%$ & $83.3 \%$ & $96.6 \%$ & 9 & $6.5 \%$ & \\
\hline
\end{tabular}

Legend: Q1: first quartile; Q3: third quartile; N: number of individuals; CI: confidence interval; SSW: staggered spondaic word test; SSI (ICM/CCM): synthetic sentence identification test (ipsilateral competing message/contralateral competing message); DPT: duration pattern test. Wilcoxon test $\mathrm{p}<0.05$. 
In Table 3, it can be observed that four behavioral measures showed statistical differences when comparing pre and post auditory training, with better performance observed after the training. Moreover, median values showed normal performance according to our analysis criteria. These changes may influence on language, academic, professional and social performance of these young adults.

In the case of the RGDT test, the average interval (in milliseconds) of the tested frequencies needed for individuals to perceive the presence of 2 sounds was lower in the assessment following FAT than in the initial assessment; however, there was no statistical significance (Table 4).

Although no statistical difference have been observed for RGDT, there was a decrease in the mean value obtained after auditory training program. These changes may help the patients in improving their auditory discrimination of subtle differences in speech perception resulting in better performance in conversations.

\section{Discussion}

Regarding the inclusion criteria, young adults were selected in order to avoid the influence of age on the behavioral assessment of CAP, as the corresponding tests are influenced by the maturation and degeneration processes of the central auditory pathway. Furthermore, right-handed individuals were selected because hand dominance also affects this assessment. Individuals not undergoing any speech, language or occupational therapy intervention before the assessment and with the minimum schooling corresponding to complete secondary education were selected aiming at equal times for a similar formation. Individuals could not have any evident physical, cognitive and psychological problem to avoid that any of these variations affected their capacity to perform the rehabilitation process (FAT).

Regarding the length of injury, periods from 6 months to 2 years after TBI were established to avoid the influence of the spontaneous recovery that follows brain injury, which occurs within the first 3 months in the case of TBI [4].

Table 4. Performance in RGDT (interval in milliseconds) before and after FAT.

\begin{tabular}{ccc}
\hline RGDT & Before & After \\
\hline Mean & 12.17 & 9.64 \\
Median & 8.0 & 8.0 \\
Standard deviation & 11.37 & 7.08 \\
Q1 & 5.5 & 5.0 \\
Q3 & 12.5 & 10.0 \\
N & 9 & 9 \\
CI & 7.43 & 4.63 \\
p-value & & 0.866 \\
\hline
\end{tabular}

Legend: Q1: first quartile; Q3: third quartile; N: number of individuals; CI: confidence interval. Wilcoxon test $\mathrm{p}<0.05$. 
Following that period and for up to two years, the brain can modify and readjust itself through stimulation-induced neuronal plasticity [28].

As for the type of lesion, diffuse axonal injury was selected as inclusion criterion because it affects the neural fibers, causing distension and rupture of axons in the brain as a whole, and it may affect several areas, such as the cortical and subcortical auditory regions [2]. The associated focal lesions in the present sample mostly corresponded to subdural hematomas, and the frontal and temporal lobes were most frequently affected by the biomechanical strength of the trauma. Notably, because both subdural hematomas and diffuse axonal injury are caused by the acceleration and deceleration mechanism of the head, their association is common [29].

Study observed a deterioration of associative memory in left upper and frontal orbital area of left cortex [30] among patients with axonal injury after TBI. However, intact memory was observed with post TBI lesion in the temporal region under incidental to intentional activities as learning conditions [31].

As for electrophysiological assessment of CAP, the BAEP showed a statistically significant reduction of absolute latencies of waves III and V and of interpeak interval I-V when compared to the assessment before FAT (Table 1). This means that improvement of the more central components of the BAEP took place. These results may reflect an objective measurement of neuronal plasticity induced by FAT because, auditory training (AT) activates the auditory and associated systems [32], resulting in beneficial alterations of the auditory behavior and the central auditory nervous system (CANS). The changes observed in latency and/or amplitude of the AEP following AT are caused by excitation of a large number of neurons and greater neuronal synchrony [12].

Several authors have recommend the use of AEP to monitor neurophysiological changes induced by AT [9] [10] [11], and LLAEP is the most widely used potential for that purpose, as neuronal plasticity varies along the auditory pathway and it is greatest in cortical regions [13] [14]. Consequently, few studies have used the BAEP click to monitor changes induced by FAT. On the other hand, studies using BAEP along with speech stimulation (BAEP-C) did not find significant alterations after training [13] [14] [33]. The only one study that used click stimulation [16] reported an improvement of the BAEP after FAT among children with CAPD. Nevertheless, based on the results of the present study, one can safely assert that BAEP is a reliable tool to measure stimulation-induced neuronal plasticity, and it should thus be included in monitoring studies following an intervention.

Previous studies using LLAEP to assess the neurophysiological changes that occur after AT found improvements of amplitude, latency, and/or morphology of waves as a function of the auditory stimulation. However, there is not a consensus on which measurement, i.e., either amplitude or latency, is more sensitive for detecting neuronal plasticity [7] [10] [11] [13] [14] [15] [17] [34]. The present study did not find significant differences neither of amplitude nor latency of P300 - LLAEP before and after the FAT (Table 2). 
The appearance of the potential P3 appears in different latencies by age group after performing a task that requires attention. In this way, the greater the age, the longer the latency; a relationship between the auditory cortex and cognition, such as memory and auditory attention, is observed. The latency of the P300 wave is an indicator of the speed of cortical processing and is quite prolonged in cases of cognitive deterioration [35].

Behavioral assessment of the AP (Table 3) showed significant improvements of the individuals' performance in the SSW, SSI-ICM and DPT behavioral tests. Furthermore, the average performance in the SSW and DPT tests shifted from altered to normal state, representing adequacy of the auditory figure-ground skill for words and temporal ordering skill, respectively.

The RGDT test (Table 4) showed that the average interval (in milliseconds)of the frequencies needed for individuals to perceive the presence of 2 sounds was lower after FAT compared to the initial assessment, although no statistically significance was found. Nevertheless, the individuals' average performance shifted from altered to normal state after FAT. This denotes the adequacy of auditory temporal resolution skills, which are associated with phonologic and auditory discrimination features, essential for effective communication and consequently important for social, academic and professional development.

Intense FAT in increasing order of complexity maximizes cortical plasticity and leads to learning [36]. In the present study, FAT was performed under these conditions, and behavioral results showed that FAT induced neuronal plasticity, leading to a behavioral change. Several authors have reported improvements of auditory skills following FAT due to changes in the neural substrate, thus in line with the present results and indicating the use of FAT as a tool for the rehabilitation of central auditory disorders, as studies have shown that the CNS can be modified by AT [17]-[22]. However, there are notably few studies with TBI patients in order to corroborate or not the evidence for significant behavioral changes related to auditory abilities after FAT.

In the present study, the reassessment was performed soon after the end of the training (approximately one week later). According to some studies, the neural changes often precede the behavioral ones [8] [9]. This indicates that reassessments carried out in even later moments could have detected an even greater improvement of auditory skills. When trained individuals are exposed to activities with high auditory demands, the environment itself enhances the improvement and even pushes it forward. Therefore, it is important to guide patients to expose themselves to several activities, particularly the most difficult ones, after they undergo FAT. The abovementioned studies further observed that when the behavioral tests indicate improvement while electrophysiological tests do not, an alternative neural pathway might have been recruited. This phenomenon may explain the lack of significant difference on the LLAEP in the present study, i.e., individuals with brain damage may have activated adjacent auditory cortical areas after FAT.

Study observed that whenever rehabilitation results in electrophysiological 
and behavioral changes, the strategy of intervention can be considered successful [6]. This was the case of the present study, as behavioral tests of the AP and the BAEP indicated improvements in spite of the lack of significant difference on the LLAEP. Therefore, one could infer that FAT was effective in the rehabilitation of central auditory disorders of TBI patients, thus agreeing with study [27] who found symptom improvements in the behavioral and electrophysiological assessments of AP following AT in a female patient with mild TBI.

Neuronal plasticity is known to differ between individuals with and without brain injury; however, the present study showed that FAT was efficient in the induction of neuronal plasticity by means of stimulation in individuals with TBI, turning auditory skills adequate and at least partially compensating for the cognitive, metacognitive and metalinguistic deficits of patients, as explained by $\mathrm{Mu}$ siek and Chermak [2]. Thus, FAT might contribute to a better adaptation of these individuals to their environment.

Based on the data described above, the importance of not only assessing the central auditory pathway of individuals with TBI but also subjecting them to a program of auditory rehabilitation becomes clear. Thus, neurologists should pay closer attention to this population in first moments but then audiologists should also be involved in the treatment. As studies on this subject are scarce, further studies are needed with patients exhibiting different degrees of severity of lesions in order to establish the need to assess and rehabilitate them and to monitor the improvement of auditory skills and its repercussions on the patients' speech.

As limitations of the study, it could be pointed out the sample size justified in this study by the inclusion criteria, since the authors chose to have a homogeneous sample considering neurological damage. Another point which could be worth to mention, was that no subjective measure was used in order to verify the patient's opinion about their improvements.

\section{Conclusion}

Individuals with diffuse axonal injury following severe traumatic brain injury exhibit an improvement of central auditory processing after formal auditory training, as evidenced by electrophysiological and behavioral assessments.

\section{Conflict of Interest}

This paper was presented in the American Academy of Audiology's annual meeting, during April 3 - 6, 2013, in Anaheim, California, at the Anaheim Convention Center (ACC).

\section{Funding Agency}

São Paulo Research Foundation/Fundação de Amparo à Pesquisa do Estado de São Paulo (FAPESP).

\section{References}

[1] Braga, F.M. and Ferraz, F.A.P. (1995) Traumatic Brain Injury (TBI). In: Prado, F.C., 
Ramos J. and Valle, J.R., Eds., Therapeutic Updates. Practical Manual of Diagnosis and Treatment, Livraria Editora Artes Médicas Ltda, São Paulo, 728-730.

[2] Musiek, F.E. and Chermak, G. (2008) Testing and Treating (C) APD in Head Injury Patients. The Hearing Journal, 61, 36-38. https://doi.org/10.1097/01.HJ.0000324322.06758.14

[3] Bergemalm, P.O. and Lyxell, B. (2005) Appearances are Deceptive: Long-Term Cognitive and Central Auditory Sequelae from Closed Head Injury. International Journal of Audiology, 44, 39-49. https://doi.org/10.1080/14992020400022546

[4] Lendrem, W. and Lincon, N.B. (1985) Spontaneous Recovery of Language in Patients with Aphasia between 4 and 34 Weeks after Stroke. Neurosurgery \& Psychiatry, 48, 743-748. https://doi.org/10.1136/jnnp.48.8.743

[5] Nudo, J. (2011) Neural Bases of Recovery after Brain Injury. Journal of Communication Disorder, 44, 515-520. https://doi.org/10.1016/j.jcomdis.2011.04.004

[6] Musiek, F.E. and Berge, B.E. (1998) A Neuroscience View of Auditory Training/Stimulation and Central Auditory Processing Disorders. In: Masters, M.G., Stecker, N.A. and Katz, J., Eds., Central Auditory Processing Disorders-Mostly Management, Allyn and Bacon, Boston, 15-32.

[7] Jirsa, R.E. (1992) The Clinical Utility of the P3 AERP in Children with Auditory Processing Disorders. Journal of Speech and Hearing Research, 35, 903-912. https://doi.org/10.1044/jshr.3504.903

[8] Tremblay, K., Kraus, N. and McGee, T. (1998) The Time Course of Auditory Perceptual Learning: Neurophysiological Changes during Speech-Sound Training. NeuroReport, 9, 3557-3560. https://doi.org/10.1097/00001756-199811160-00003

[9] Kraus, N. (1999) Speech-Sound Perceptual Learning. The Hearing Journal, 52, 64-66. https://doi.org/10.1097/00025572-199911000-00009

[10] Tremblay, K.L. and Kraus, N. (2002) Auditory Training Induces Asymmetrical Changes in Cortical Neural Activity. Journal of Speech, Language, and Hearing Research, 45, 564-572. https://doi.org/10.1044/1092-4388(2002/045)

[11] Musiek, F.E., Shinn, J. and Hare, C. (2002) Plasticity, Auditory Training and Auditory Processing Disorders. Seminars in Hearing, 23, 264-275. https://doi.org/10.1055/s-2002-35862

[12] Cone-Wesson, B. and Wunderlich, J. (2003) Auditory Evoked Potentials from the Cortex: Audiology Applications. Current Opinion on Otolaryngology and Head and Neck Surgery, 11, 372-377. https://doi.org/10.1097/00020840-200310000-00011

[13] Hayes, E.A., Warrier, C.M., Nicol, T.G., Zecker, S.G. and Kraus, N. (2003) Neural Plasticity Following Auditory Training with Learning Problems. Clinical Neurophysiology, 114, 673-684. https://doi.org/10.1016/s1388-2457(02)00414-5

[14] Russo, N.M., Nicol, T.G., Zecker, S.G., Ilayes, E.A. and Kraus, N. (2005) Auditory Training Improves Neural Timing in the Human Brainstem. Behavioral Brain Research, 156, 95-103. https://doi.org/10.1016/j.bbr.2004.05.012

[15] Alonso, R. and Schochat, E. (2009) The Efficacy of Formal Auditory Training in Children with (Central) Auditory Processing Disorder: Behavioral and Electrophysiological Evaluation. Brazilian Journal of Otorhinolaryngology, 75, 726-732. https://doi.org/10.1016/S1808-8694(15)30525-5

[16] Vieira, H.S. and Reis, A.C.M.B. (2009) Assessment of the Effectiveness of Auditory Training in a Group of Children with Auditory Processing Disorder. Trabalho de conclusão de curso.

[17] Gil, D. And Iorio, M.C.M. (2010) Formal Auditory Training in Adult Hearing Aid 
Users. Clinics, 65, 165-174. https://doi.org/10.1590/S1807-59322010000200008

[18] Musiek, F.E. and Schochat, E. (1998) Auditory Training and Central Auditory Processing Disorders-a Case Study. Seminars in Hearing, 19, 357-365. https://doi.org/10.1055/s-0028-1082983

[19] Zalcman, T.E. and Schochat, E. (2007) Formal Auditory Training Efficacy in Individuals with Auditory Processing Disorder. Revista da Sociedade Brasileira de Fonoaudiologia, 12, 310-314. https://doi.org/10.1590/S1516-80342007000400010

[20] Pinheiro, F.H. and Capellini, S.A. (2010) Auditory Training in Students with Learning Disabilities. Pró-Fono Revista de Atualização Científica, 22, 49-54. https://doi.org/10.1590/S0104-56872010000100010

[21] Ziliotto, Z.N. and Pereira, L.D. (2007) Auditory Stimulation in Acoustic Booth: Case Report. In: Pereira, L.D., Azevedo, M.F., Machado, L.P., Ziliotto, K.N., Ed., Auditory Processing: Speech Therapy. A Rehabilitation Approach, Lovise, São Paulo.

[22] Cruz, A.C.A., Andrade, A.N. and Gil, D. (2013) The Efficacy of Formal Auditory Training in Adults with Central Auditory Processing Disorder. Revista CEFAC, 15, 1427-1434. https://doi.org/10.1590/S1516-18462013000600004

[23] Song, J.H., Skoe, E., Banai, K. and Kraus, N. (2012) Training to Improve Hearing Speech in Noise: Biological Mechanisms. Cerebral Cortex, 22, 1180-1190. https://doi.org/10.1093/cercor/bhr196

[24] Anderson, S., White-Schwoch, T., Choi, H.J. and Kraus, N. (2014) Partial Maintenance of Auditory-Based Cognitive Training Benefits in Older Adults. Neuropsychologia, 62, 286-296. https://doi.org/10.1016/i.neuropsychologia.2014.07.034

[25] Pereira, L.D. and Dias, K.Z. (2009) Speech Therapy in Auditory Processing Disorders Focused on Auditory-Verbal Training. In: Cesar, A.M., Maksud, S.S., Fundamentals and Practices in Speech Therapy, Revinte, Rio de Janeiro, 137-148.

[26] Dias, K.Z. and Gil, D. (2011) Formal Auditory Training in Auditory Processing Disorders. In: Bevilacqua, MC, Martinez MA, Balen SA, et al, Treatise on Audiology, Santos Editora, Santos, 828-844.

[27] Musiek, F.E. (2004) The DIID: A New Treatment for APD. The Hearing Journal, 57, 50. https://doi.org/10.1097/01.HJ.0000293049.80297.cd

[28] Santos, C.B., Figueiredo, E.G. and Teixeira, M.J. (2011) Cognitive Rehabilitation and Head Injury. Arquivos Brasileiros de Neurocirurgia, 30, 51-54.

[29] Teasdale, G. and Mathew, P. (1996) Mechanisms of Cerebral Concussion, Contusion and Other Effects of Head Injury. In: Youmans, J.R., Ed., Neurological Surgery, W.B. Saunders Co., New York, 1533-1546.

[30] Fagerholm, E.D., Hellyer, P.J., Scott, G., Leech, R. and Sharp, D.J. (2015) Disconnection of Network Hubs and Cognitive Impairment after Traumatic Brain Injury. Brain, 138, 1696-1709. https://doi.org/10.1093/brain/awv075

[31] Wright, M.J., Wong, A.L., Obermeit, L.C., Woo, E., Schmitter-Edgecombe, M., and Fuster, J.M. (2014) Memory for Performed and Observed Activities Following Traumatic Brain Injury. Journal of Clinical and Experimental Neuropsychology, 36, 268-277. https://doi.org/10.1080/13803395.2014.884543

[32] Musiek, F.E. and Berge, B.E. (1998) How Electrophysiologic Tests of Central Auditory Processing Influence Management. In: Bess, F., Ed., Children with Hearing Impairment, Bill Wilkerson Center Press, Nashville, 145-162.

[33] Song, J.H., Nicola, T. and Kraus, N. (2011) Test-Retest Reliability of the SpeechEvoked Auditory Brainstem Response in Young Adults. Clinical Neurophysiology, 
122, 346-355. https://doi.org/10.1016/j.clinph.2010.07.009

[34] Tremblay, K., Kraus, N., McGee, T., Ponton, C. and Otis, B. (2001) Central Auditory Plasticity: Changes in N1-P2 Complex after Speech-Sound Training. Ear and Hear, 22, 79-90. https://doi.org/10.1097/00003446-200104000-00001

[35] Souza, L.C.A., Piza, M.R.T., Alvarenga, K.F. and Cóser, P.L. (2016) Electrophysiology of Hearing and Otoacoustic Emissions: Principles and Clinical Applications. 3rd Edition, Editora Booktoy, São Paulo, 95-109.

[36] Merzenich, M.M., Jenkins, W.M., Johnston, P., Schreiner, C., Miller, S.L. and Tallal, P. (1996) Temporal Processing Deficits of Language-Impaired Children Ameliorated by Training. Science, 271, 77-80. https://doi.org/10.1126/science.271.5245.77

Submit or recommend next manuscript to SCIRP and we will provide best service for you:

Accepting pre-submission inquiries through Email, Facebook, LinkedIn, Twitter, etc. A wide selection of journals (inclusive of 9 subjects, more than 200 journals)

Providing 24-hour high-quality service

User-friendly online submission system

Fair and swift peer-review system

Efficient typesetting and proofreading procedure

Display of the result of downloads and visits, as well as the number of cited articles Maximum dissemination of your research work

Submit your manuscript at: http://papersubmission.scirp.org/

Or contact health@scirp.org 